\title{
CAPS Facilitates Filling of the Rapidly Releasable Pool of Large Dense-Core Vesicles
}

\author{
Yuanyuan Liu, ${ }^{1}$ Claudia Schirra, ${ }^{1}$ David R. Stevens, ${ }^{1}$ Ulf Matti, ${ }^{1}$ Dina Speidel,, 2 Detlef Hof, ${ }^{1}$ Dieter Bruns, ${ }^{1}$ Nils Brose, ${ }^{2}$ \\ and Jens Rettig ${ }^{1}$ \\ ${ }^{1}$ Institut für Physiologie, Universität des Saarlandes, D-66421 Homburg/Saar, Germany, and 2Max-Planck-Institut für Experimentelle Medizin, Abteilung \\ Molekulare Neurobiologie, D-37075 Göttingen, Germany
}

\begin{abstract}
Calcium-activator protein for secretion (CAPS) is a cytosolic protein that associates with large dense-core vesicles and is involved in their secretion. Mammals express two CAPS isoforms, which share a similar domain structure including a Munc13 homology domain that is believed to be involved in the priming of secretory vesicles. A variety of studies designed to perturb CAPS function indicate that CAPS is involved in the secretion of large dense-core vesicles, but where in the secretory pathway CAPS acts is still under debate. Mice in which one allele of the CAPS-1 gene is deleted exhibit a deficit in catecholamine secretion from chromaffin cells. We have examined catecholamine secretion from chromaffin cells in which both CAPS genes were deleted and show that the deletion of both CAPS isoforms causes a strong reduction in the pool of rapidly releasable chromaffin granules and of sustained release during ongoing stimulation. We conclude that CAPS is required for the adequate refilling and/or maintenance of a rapidly releasable granule pool.
\end{abstract}

Key words: exocytosis; priming; docking; rapidly releasable pool; slowly releasable pool; chromaffin cell

\section{Introduction}

Calcium-activator protein for secretion (CAPS) is a soluble factor that reconstitutes calcium-dependent secretion in permeabilized and cytosol-deprived PC12 cells (Hay and Martin, 1992; Walent et al., 1992). CAPS homologs in Caenorhabditis elegans (Unc-31) (Avery et al., 1993) and in Drosophila (dCAPS) (Renden et al., 2001) are involved in nervous system function because their inactivation leads to nervous system and motor deficits. CAPS proteins are present in the cytosol, associate with large dense-core vesicles (LDCVs) in neurons and neuroendocrine cells, and function in LDCV exocytosis (Ann et al., 1997; Berwin et al., 1998; Tandon et al., 1998; Elhamdani et al., 1999; Rupnik et al., 2000; Grishanin et al., 2002, 2004).

Mammals express two CAPS isoforms that are highly homologous to Unc-31 and dCAPS and contain a coiled-coil domain with similarity to Unc-13/Munc-13 [Munc13 homology domain (MHD)] (Koch et al., 2000; Cisternas et al., 2003; Speidel et al., 2003). Unc-13/Munc-13 functions in priming of synaptic vesicles (SVs) in Drosophila (Aravamudan et al., 1999), C. elegans (Richmond et al., 1999), and mouse (Augustin et al., 1999). Munc13-1 also enhances priming of chromaffin granules and insulin gran-

Received Dec. 21, 2007; revised March 20, 2008; accepted April 17, 2008.

This work was supported by grants from the Deutsche Forschungsgemeinschaft (SFB 530, GRK 845, and GRK 1326 to D.B. and J.R.) and by the Homburger Forschungsförderungsprogramm. We thank C. Bick, P. Jochem, K. Sandmeier, M. Schneider, and R. Trautmann for expert technical support and G. Kiefer and F. Schmitz for help with electron microscopy.

Correspondence should be addressed to Dr. Jens Rettig, Institut für Physiologie, Universität des Saarlandes, Gebäude 59, Kirrberger Strasse 8, 66421 Homburg/Saar, Germany. E-mail: jrettig@uks.eu.

D. Speidel's present address: Department of Clinical Sciences Malmö, Lund University, UMAS Ing 72, CRC 91-11, S-20502 Malmö, Sweden.

DOI:10.1523/JNEUROSCI.5672-07.2008

Copyright $\odot 2008$ Society for Neuroscience $\quad$ 0270-6474/08/285594-08\$15.00/0 ules (Ashery et al., 2000; Kang et al., 2006). The priming action of Munc13s depends on the presence of a region containing its two MHDs (Basu et al., 2005; Madison et al., 2005; Stevens et al., 2005).

The presence of a conserved MHD in CAPS reinforces the possibility that CAPS functions similarly to the UNC-13 proteins. CAPS is involved in LDCV secretion but does not appear to be directly involved in SV secretion in C. elegans (Speese et al., 2007), although there is a deficit in neuromuscular transmission after mutation of unc-31 in this organism (Gracheva et al., 2007). Although defects in SV secretion accompany CAPS deletion in Drosophila (Renden et al., 2001) as well, the inability to rescue neurotransmission by expression of dCAPS was considered evidence that the observed deficit was not directly attributable to the absence of this CAPS family member.

The results are consistent with a role for CAPS in LDCV secretion, possibly in the priming process. The consensus that CAPS is involved directly only in LDCV secretion and not in SV secretion has been challenged recently (Jokusch et al., 2007). In PC1 2 cells, knockdown of CAPS- 1 reduces both stimulated and constitutive LDCV exocytosis, indicating a role in priming (Fujita et al., 2007). We recently reported that deletion of CAPS-1 causes a deficit in catecholamine secretion from mouse chromaffin cells and leads to fusion of LDCVs containing no catecholamines, indicating a role of CAPS- 1 in catecholamine loading as well as in secretion (Speidel et al., 2005). Because the reduction in release we observed in chromaffin cells from CAPS-1 knock-out mice was probably mitigated by the presence of CAPS-2, we have now examined secretion of catecholamines in mouse chromaffin cells deficient in both CAPS- 1 and CAPS- 2 . We show that deletion of both CAPS-1 and CAPS-2 leads to a severe deficit in LDCV secretion because of a deficit in filling of 
the rapidly releasable pool (RRP) in mouse chromaffin cells. These results indicate that CAPS either facilitates the conversion of slowly releasable vesicles into rapidly releasable vesicles or stabilizes the rapidly releasable state.

\section{Materials and Methods}

Mice with a deletion of the mouse CAPS-1 protein (CAPS- 1 knock-out) have been described previously (Speidel et al., 2005). Deletion of the CAPS-2 gene in mice was described recently (Jokusch et al., 2007). CAPS$1 /-2$ double knock-out (DKO) mice were generated by breeding the CAPS-1 mutation into the CAPS-2 mutant background. Genotype was confirmed by PCR using primers as described previously (Speidel et al., 2005; Jokusch et al., 2007).

Chromaffin cell preparation and infection. All electrophysiological experiments were performed on mouse chromaffin cells in primary culture. The cells were prepared as described previously (Sorensen et al., 2002). Embryos [embryonic day 18 (E18) and E19] were prepared after cesarean section after cervical dislocation. Embryos were decapitated and placed on ice, and adrenal glands were rapidly removed and placed in cold Locke's solution. After cooling, the glands were incubated for $20 \mathrm{~min}$ in a DMEM solution containing $20 \mathrm{U} / \mathrm{ml}$ papain (Roche). The glands were washed in an inactivating solution (DMEM plus 10\% BSA) after the removal of the papain solution. After $4 \mathrm{~min}$ in the inactivating solution, the glands were triturated and plated on glass coverslips. Thirty minutes later, $3 \mathrm{ml}$ of DMEM was added to the wells containing the coverslips, and the cells were incubated for up to $4 \mathrm{~d}$ at $37^{\circ} \mathrm{C}$ in DMEM gassed with $8 \% \mathrm{CO}_{2}$. For the CAPS-1 rescue experiment, isolated chromaffin cells were infected with $50 \mu \mathrm{l}$ of activated pSFV1-CAPS1-GFP following a protocol described previously (Ashery et al., 1999).

Electron microscopy. Acutely dissociated chromaffin cells from wild type of CAPS DKO mice (E18) were plated on Petriperm dishes (SigmaAldrich). After $2 \mathrm{~d}$ in culture, the cells were fixed with $3 \%$ glutaraldehyde and $2 \%$ paraformaldehyde in $0.1 \mathrm{M}$ cacodylate buffer, $\mathrm{pH} 7.4$; treated with $2 \% \mathrm{OsO}_{4}$ in $0.1 \mathrm{~m}$ cacodylate buffer, $\mathrm{pH} 7.4$, for $1 \mathrm{~h}$; serially dehydrated in ethanol, followed by infiltration with Embed-812 (Electron Microscopy Sciences); and polymerized for $48 \mathrm{~h}$ at $60^{\circ} \mathrm{C}$. Ultrathin sections $(70 \mathrm{~nm})$ were collected on single-slot, pioloform-coated grids; poststained ( $2 \%$ uranyl acetate for $10 \mathrm{~min}$ and lead citrate for $5 \mathrm{~min}$ ); and analyzed with a Philips Tecnai12 Biotwin electron microscope. An outline of both the plasma membrane and the nucleus was generated manually. Each vesicle was marked, and the shortest distance of its center to the plasma membrane was determined.

Patch-clamp analyses. Conventional whole-cell recordings were performed with 4-6 M $\Omega$ pipettes using an EPC-9 patch-clamp amplifier controlled with Pulse software (HEKA). The extracellular solution contained $145 \mathrm{~mm} \mathrm{NaCl}, 2.4 \mathrm{~mm} \mathrm{KCl}, 10 \mathrm{~mm}$ HEPES, $4 \mathrm{~mm} \mathrm{MgCl}_{2}, 1 \mathrm{~mm}$ $\mathrm{CaCl}_{2}$, and $10 \mathrm{~mm}$ glucose, $\mathrm{pH}$ 7.4. The intracellular solution contained $100 \mathrm{~mm}$ Cs-glutamate, $2 \mathrm{~mm} \mathrm{Mg}$-ATP, $0.3 \mathrm{~mm} \mathrm{Na}_{2}$-GTP, $40 \mathrm{~mm}$ CsHEPES, $5 \mathrm{~mm}$ nitrophenyl-EGTA (NP-EGTA), $4 \mathrm{~mm} \mathrm{CaCl}_{2}, 0.4 \mathrm{~mm}$ Furaptra, and 0.4 mm Fura-4F, pH 7.2. Capacitance measurements were performed using the Lindau-Neher technique implemented as the "sine $+\mathrm{dc}$ " mode of the "software lock-in" extension of Pulse software. A $1 \mathrm{kHz}, 70 \mathrm{mV}$ peak-to-peak sinusoid stimulus was applied at a DC holding potential of $-70 \mathrm{mV}$. All experiments were performed at room temperature. Data are shown as mean \pm SEM. We used the Mann-Whitney $U$ test for comparison of differences between groups. Curve fits were done using IGOR Pro (Wavemetrics).

Measurements of $\left[\mathrm{Ca}^{2+}\right]_{i}$ and photolysis of caged $\mathrm{Ca}^{2+} \cdot\left[\mathrm{Ca}^{2+}\right]_{\mathrm{i}}$ was measured using a mixture of two indicator dyes, Fura- $4 \mathrm{~F}$ and Furaptra. The dyes were excited with UV illumination alternated between 350 and $380 \mathrm{~nm}$ using a monochromator-based system, and the fluorescent signal was measured using a photomultiplier (T.I.L.L. Photonics). The ratio of the fluorescent signals was converted to $\left[\mathrm{Ca}^{2+}\right]_{\mathrm{i}}$, using an in vivo calibration curve (Voets, 2000). To obtain stepwise increases in $\left[\mathrm{Ca}^{2+}\right]_{\mathrm{i}}$, short flashes of UV light from a xenon arc flash lamp (Rapp OptoElectronics) were applied to the whole cell. The monochromator was not only used to measure $\left[\mathrm{Ca}^{2+}\right]_{\mathrm{i}}$ but also used to maintain calcium levels for $5 \mathrm{~s}$ after the flash (see Figs. 1,6) and allowed us to adjust $\left[\mathrm{Ca}^{2+}\right]_{\mathrm{i}}$ after a flash or to achieve calcium ramps by photolyzing smaller amounts of NP-EGTA. Trains of illumination at 350 and $380 \mathrm{~nm}$ for ratio measurement of calcium were generated via the monochromator.

Amperometric recordings of catecholamines. Carbon fiber electrodes used for amperometry were produced as follows. Carbon fibers $(5 \mu \mathrm{m}$ diameter) were glued to copper cannulas using a conducting carbon paste (Bavaria Elektronik) and were glued inside a glass pipette. The pipettes were then pulled with a conventional puller. The carbon fiber extending beyond the pulled pipette tip was coated with a cathodal paint by electrolysis (BASF). The assembly was then baked for $20 \mathrm{~min}$ at $50^{\circ} \mathrm{C}$. The junction between the fiber and the glass was sealed with Sylgard and baked again at $50^{\circ} \mathrm{C}$. Before use, the carbon fibers were broken off to expose the tip for recording. The electrode was connected to the head stage of an EPC7 patch-clamp amplifier (HEKA), and a holding potential of $+800 \mathrm{mV}$ was applied in the voltage-clamp mode. The carbon fiber was positioned so that it lightly touched the cell that was being recorded. Catecholamines contacting the carbon fiber were immediately oxidized, producing a potential at the fiber that was countered by the patch clamp and allowing recording of catecholamine release as a measure of the amperometric current.

\section{Results}

We have compared secretion in CAPS DKO mice with that observed in wild-type cells. By combining flash photolysis, which allows immediate, global increases in calcium, with ratiometric calcium monitoring, we bypassed problems of microdomains while confirming that intracellular calcium levels in controls and DKO mice were comparable.

After flash photolysis, the intracellular free calcium was raised instantly from the resting level of $\sim 450 \mathrm{nM}$ to $\sim 20 \mu \mathrm{M}$. This increase in calcium caused fusion of catecholamine-containing vesicles, leading to an increase in cell capacitance (Fig. 1, $\Delta C_{\mathrm{m}}$ ). The cumulative charge $\left(Q_{\mathrm{amp}}\right)$ measured by the carbon fiber is shown in the third trace. Secretion as measured either by capacitance change or amperometric charge was less in the CAPS DKO cells than that observed in the wild-type cells (46 and $38 \%$ of wild-type values, respectively). The relatively larger reduction in amperometric current can be attributed to the influence of CAPS on vesicle filling (presence of empty vesicles) as reported previously (Speidel et al., 2005).

Exocytosis of LDCVs in chromaffin cells is a highly regulated event consisting of a burst phase and a sustained phase. The burst phase consists of release of an RRP and a slowly releasing pool (SRP) of vesicles. The sustained release phase is attributable to maturation (priming) of LDCVs that were not primed at the time of the initial calcium increase, followed by their fusion (Rettig and Neher, 2002; Burgoyne and Morgan, 2003; Sorensen, 2004). The responses were fit as the sum of two exponentials, one each for the RRP and SRP, and a linear component of sustained release. Summarized results are shown in Figure $1 B$. The burst phase of vesicle fusion in wild-type chromaffin cells was measured as a capacitance change of $153.4 \mathrm{fF}(n=30)$, with $65.4 \pm 8.3$ $\mathrm{fF}$ contributed by the RRP and $88 \pm 17.3 \mathrm{fF}$ contributed by the SRP. The sustained release in the wild-type cells was $19.5 \pm 2.2$ $\mathrm{fF} / \mathrm{s}$. In CAPS DKO chromaffin cells, the burst phase of fusion amounted to $101.8 \mathrm{fF}(n=29)$, with $31.3 \pm 9.8 \mathrm{fF}$ attributable to the RRP and $70.5 \pm 14.5 \mathrm{fF}$ attributable to the SRP. The reduction in the RRP in CAPS DKO cells was highly significant, whereas the reduction in the SRP was not, possibly indicating a selective action of CAPS on the RRP. Sustained secretion was virtually absent $(0.5 \pm 2.1 \mathrm{fF} / \mathrm{s})$ in the DKO cells.

The release time constants for the RRPs ( $29 \pm 9 \mathrm{vs} 56 \pm 15 \mathrm{~ms})$ and SRPs ( $400 \pm 56$ vs $500 \pm 51 \mathrm{~ms})$, in wild-type and CAPS DKO chromaffin cells, respectively, were not significantly different $(p>0.05)$. The reductions in the burst amplitude and in the 

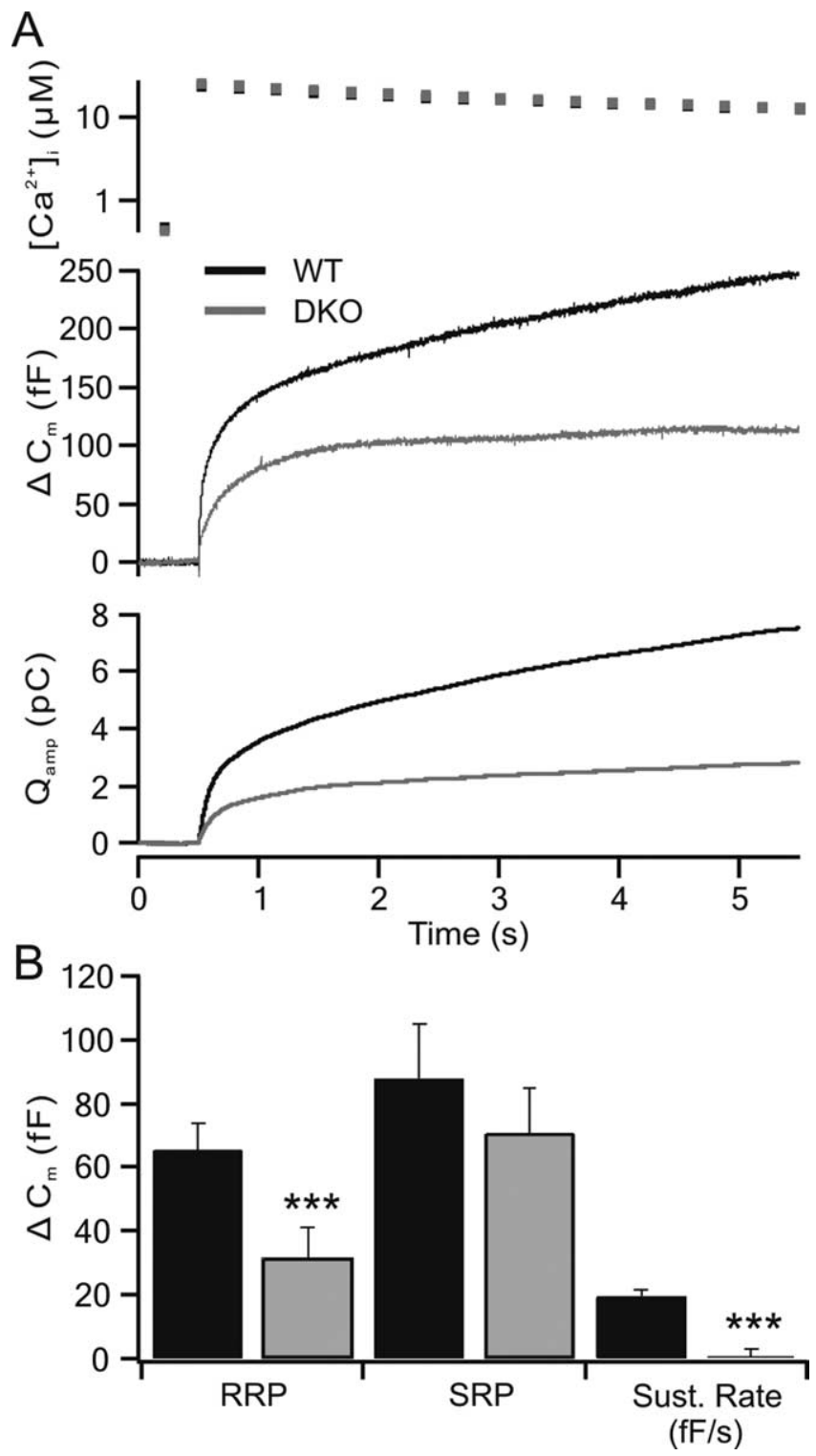

Figure 1. Catecholamine secretion is suppressed in CAPS DKO chromaffin cells compared with wild-type cells. $A$, The intracellular calcium after flash photolysis of NP-EGTA (top trace) is shown along with capacitance changes $\left(\Delta C_{m}\right)$ and cumulative charge $\left(Q_{\text {amp }}\right)$ released from chromaffin cells as determined by amperometric measurements using carbon fiber electrodes in wild-type (WT; black traces; $n=30$ ) and CAPS DKO (gray traces; $n=29$ ) chromaffin cells. Both the capacitance response and the amperometric response indicate a strong reduction in secretion in the CAPS DKO cells. $\boldsymbol{B}$, Kinetic analysis of the capacitance responses indicates that the CAPS DKO cells exhibit a significantly reduced RRP and a strong reduction in the sustained component (Sust. Rate; ${ }^{* * *} p<0.001$ ). The SRP was not significantly reduced, although the average SRP was also smaller. Error bars indicate SEM.

sustained component of release observed in CAPS DKO chromaffin cells are consistent with a deficit in available vesicles at the plasma membrane or a defect in vesicle priming.

To distinguish between these two alternatives, we quantified LDCVs in chromaffin cells using electron microscopy. We examined the density and location of LDCVs (wild type, 3281 from 28 cells; DKO, 4090 from 28 cells) with respect to the plasma membrane. Wild-type cells and CAPS DKO cells exhibited a similar distribution of vesicles (Fig. 2). The mean numbers of "morphologically docked" vesicles, those with centers within a vesicle radius $(\sim 80 \mathrm{~nm})$ of the plasma membrane, were not different in the two populations. Thus,
A
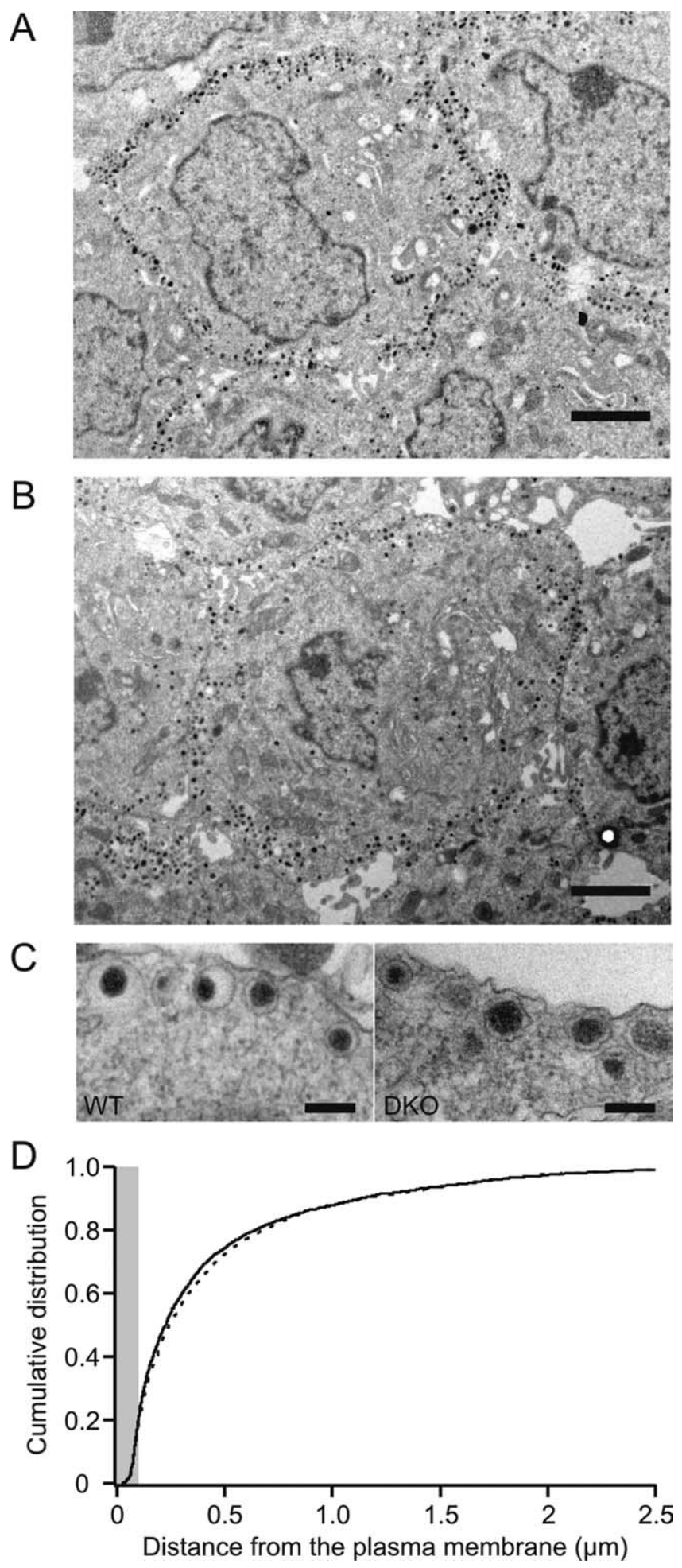

Figure 2. The distribution of LDCVs in CAPS DKO chromaffin cells is similar to that observed in wild-type chromaffin cells. $\boldsymbol{A}, \boldsymbol{B}$, Electron micrographs showing wild-type $(\boldsymbol{A})$ and CAPS DKO (B) chromaffin cells. Scale bars, $2 \mu \mathrm{m}$. C, Higher-magnification micrographs showing details of individual vesicles in chromaffin cells. Scale bars, $200 \mathrm{~nm}$. D, The cumulative distribution of distance of the midpoint of the vesicle from the plasma membrane. Although the wild-type (solid line) and DKO (dashed line) distributions were significantly different with $p<0.05$ (Kolmogorov-Smirnov test), the greatest difference was 3.3\% and occurred at a distance of 177 $\mathrm{nm}$, outside of the morphologically docked zone (radius, $100 \mathrm{~nm}$; gray). There was no significant difference in the density of vesicles with centers within a vesicle radius $(80 \mathrm{~nm})$ of the plasma membrane. WT, Wild type. 

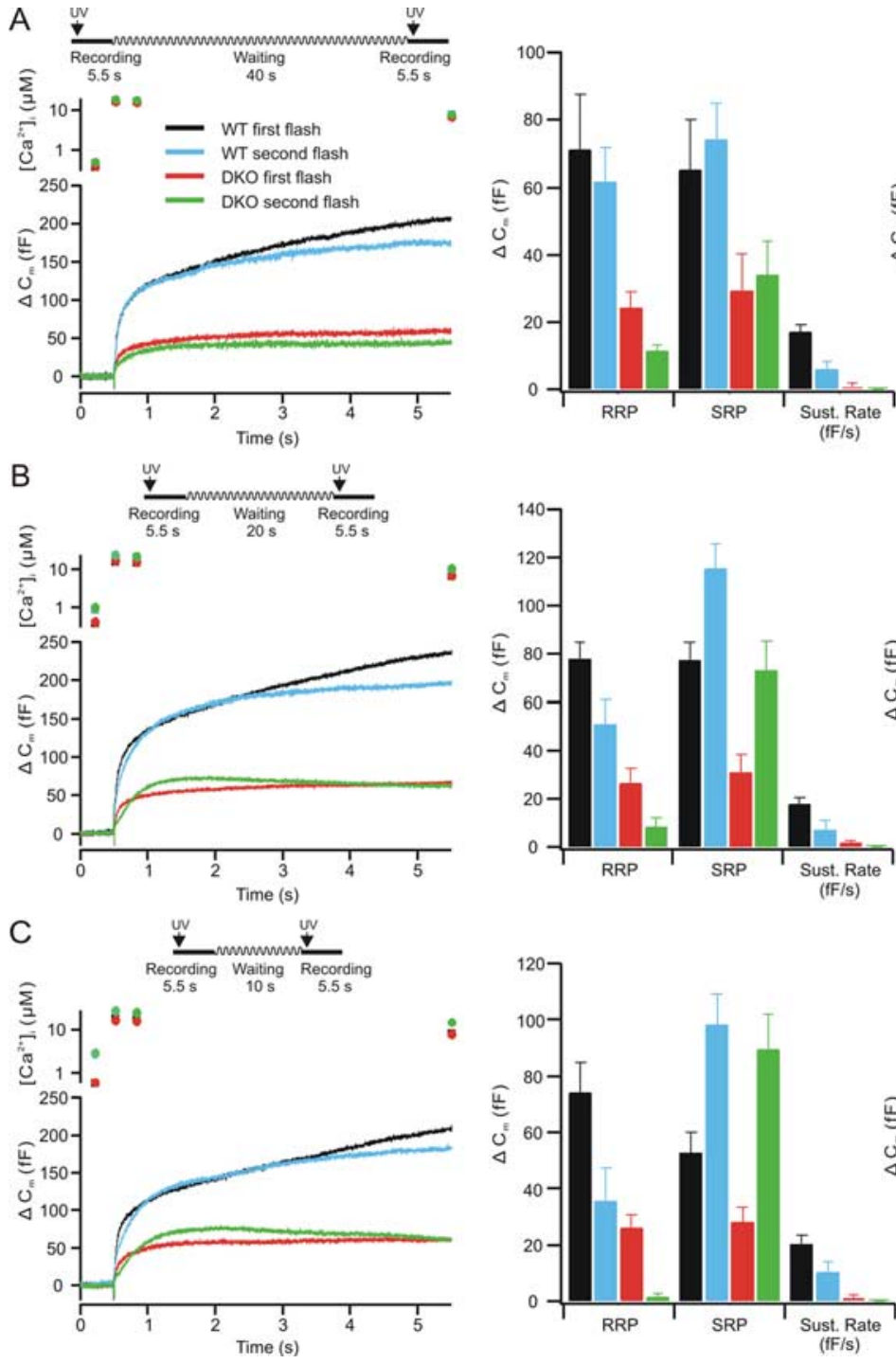

Figure 3. Responses to flash stimulation with decreasing ISIs (left traces). $A, A$ t an ISI of $45 \mathrm{~s}$, the burst phase is fully recovered in both wild-type $(n=13)$ and DKO $(n=14)$ cells. $\boldsymbol{B}$, When the ISI was shortened to $25 \mathrm{~s}$, the RRP was reduced although the SRP was enhanced in wild-type $(n=25)$ and in DKO $(n=25)$ cells, but this trend was much stronger in the CAPS DKO cells. C, At an ISI of $15 \mathrm{~s}$, the trend to smaller RRP and greater SRP was again apparent in both wild-type $(n=20)$ and DKO $(n=22)$ cells. The RRP in the CAPS DKO mice was almost nonexistent. The SRP was, in contrast, overfilled. There was no sustained component in the DKO cells, although one was present in the wild-type cells. The averages of pool sizes (mean $\pm \mathrm{SEM}$ ) for the double-flash experiments are shown in the middle traces. Wild-type (black, first flash; blue, second flash) and DKO (red, first flash; green, second flash) cells RRPs, SRPs, and sustained release rates (Sust. Rate) are shown for the 45 sinterval $(\boldsymbol{A})$, for the 25 sinterval $(\boldsymbol{B})$, and for the $15 \mathrm{~s}$ interval $(\boldsymbol{C})$. The DKO cells exhibited less secretion in all phases of the response. In addition to significantly lower secretion in the DKO cells, the sustained release was strongly reduced. At $45 \mathrm{~s}$, ISI secretion was similar to that observed at a 2 min ISI. At shorter ISIs, refilling of the RRP was strongly reduced in the CAPSDKO cells, whereas the SRP was refilled. The averaged burst responses (sum of RRP and SRP) are shown on the right and indicate that although the burst remained constant for wild-type cells, they actually were greater at short intervals in the DKO cells. Error bars indicate SEM.

the observed reduction in secretion is most likely attributable to a defect in priming rather than in docking of LDCVs.

A defect in priming efficacy would be expected to decrease not only the size of the releasable vesicle pools and sustained release, but also to reduce the degree or rate of pool recovery after stimulation. We examined the recovery of the releasable vesicle pools using paired flash stimulations (Fig. 3). In these experiments, we did not maintain calcium at high levels after the flash, but rather allowed free calcium levels to decrease after the flash to allow more rapid recovery of releasable vesicle pools. An interstimulus interval (ISI) of $2 \mathrm{~min}$ between flashes allows for the recovery of
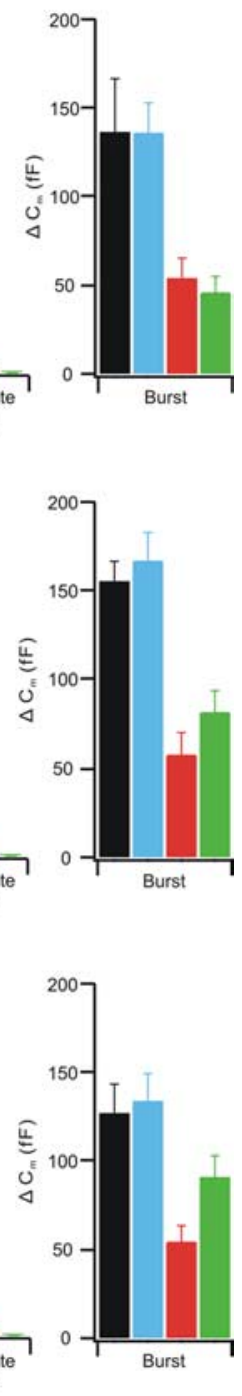

releasable vesicle pools, and the second of a pair of responses is typically quite similar to the first.

We first examined an ISI of $45 \mathrm{~s}$ (Fig. $3 A$ ). In wild-type cells, the burst amplitude after the second flash was similar to that in the first flash (Fig. $3 A$, left) with an RRP and SRP of similar amplitude (Fig. $3 A$, middle). In CAPS DKO cells, the RRP was reduced and the SRP was moderately increased after the second flash, with a net decrease in the burst phase of release. At an ISI of $25 \mathrm{~s}$ (Fig. 3B), the secretion from wild-type cells was similar to that observed at a 45 s ISI, whereas the CAPS DKO cells exhibited a marked reduction in the RRP and an overfilling of the SRP (Fig. 3B, middle), resulting in a net increase in the burst phase of release (Fig. $3 B$, right). With an ISI of $15 \mathrm{~s}$ (Fig. 3C), the wild-type cells exhibited burst responses with reduced RRP and increased SRP amplitudes in the second response, whereas the CAPS DKO cells had virtually no RRP and a more strongly enhanced SRP (Fig. 3C, middle), resulting in an even larger burst (Fig. 3C, right). There was no evidence of a sustained component in the CAPS DKO cells, with some endocytosis occurring during the second response. Notably, the burst amplitudes (Fig. 3C, right) of the wildtype responses remained constant, whereas the burst in the second flash in DKO mice increased at shorter ISIs. Thus, although the RRP refilled quite slowly in DKO mice, relative to that in the wild-type cells (Fig. 3C, middle), priming into the SRP approached wild-type levels at the $15 \mathrm{~s}$ ISI (Fig. 3C, middle). This may indicate that the SRP primes quickly but decays again at longer ISIs. There were no changes in the release kinetics of the RRP and SRP $(p>0.2)$.

The enlarged SRP at short intervals could be attributable to the increased intracellular calcium levels present between the two flashes. This is reminiscent of the temporary reversal of the deficit in transmitter release in hippocampal neurons in CAPS DKO mice when extracellular calcium was raised (Jockusch et al., 2007). We tested whether secretion in CAPS DKO cells has a different calcium requirement than that of wild-type cells. To this end, we applied a calcium "ramp" stimulus (Sorensen et al., 2002), a slowly rising calcium concentration generated by photolysis of calcium from NP-EGTA in small increments over a longer time (10 s), as opposed to the stepwise increase achieved using a flash lamp. This was done using short pulses of UV light of 350 and $380 \mathrm{~nm}$ at short intervals. The calcium ramp stimulus led to robust secretion (Fig. 4A).

The response to the ramp stimulus was sigmoid in both the wild-type and CAPS DKO cells (Fig. 4A). Scaling the release response of CAPS DKO mice to that of wild-type cells indicated a 

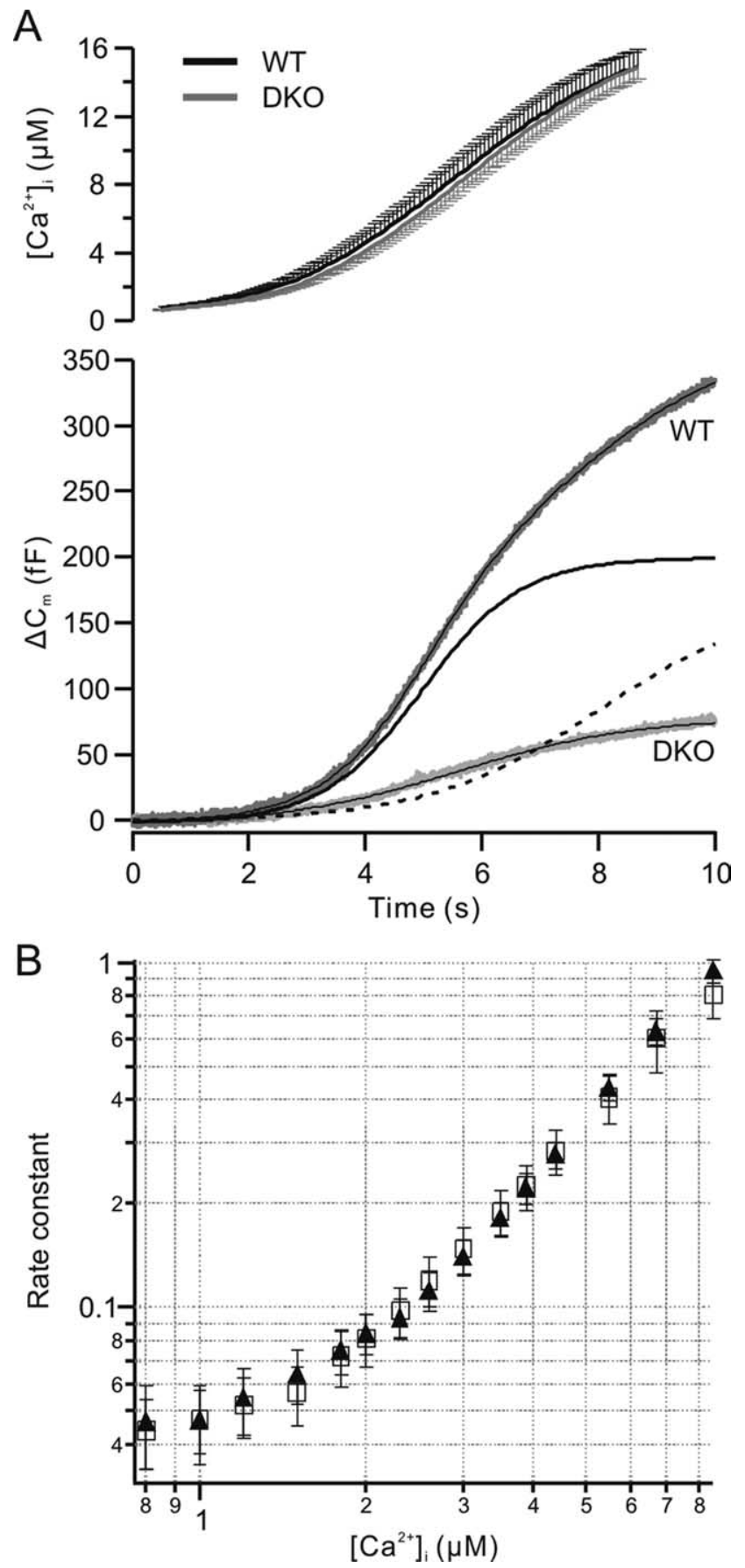

Figure 4. The calcium dependence of secretion is unchanged in CAPS DKO chromaffin cells. $A$, Ramp-like calcium increases (mean \pm SEM; top trace) lead to robust secretion in wild-type chromaffin cells (WT; $\Delta C_{m}$ ). The total mean secretion during the ramp stimulus was $334 \mathrm{fF}$ in wild-type cells $(n=15)$ and $76 \mathrm{fF}$ in CAPS DKO cells $(n=16)$. The capacitance trace of wild-type cells (gray) was fit with a dual sigmoid curve (overlaid black line), with an early phase (solid line) and a later phase (dashed line). The capacitance response of the DKO cells (light gray trace) was well fit with a single sigmoid (overlaid). $\boldsymbol{B}$, The rate constant of stimulated release (based on the capacitance change) was similar in wild-type (filled triangle) and CAPS DKO (open square) cells. The threshold for calcium-dependent secretion was not different. The results show that the calcium dependence of secretion is similar in wild-type and CAPS DKO cells and indicate that CAPS does not alter calcium sensing in the secretion phase.

slightly steeper early rising phase in the DKO cells (data not shown). The total secretion in the wild-type cells (334.4 $\pm 32.3 \mathrm{fF}$; $n=16)$ was approximately four times that in the DKO cells $(76.3 \pm 10.8 \mathrm{fF} ; n=15)$.
The secretion response in wild-type cells, although sigmoid, was best fit with the sum of two sigmoids, whereas the secretion in the CAPS DKO cells could be well fit with a single sigmoid curve (Fig. 4A). In the case of the wild-type cells, the first component had a midpoint near $5 \mathrm{~s}$ and consisted of $198 \mathrm{fF}$. This component likely represents the burst response. The additional secretion is likely attributable to sustained release. The sigmoid fit for the CAPS DKO cells had a midpoint near $5.6 \mathrm{~s}$ and likely consists of only a burst response of $\sim 80 \mathrm{fF}$. The thresholds for calciuminduced secretion during the ramp stimulation were similar $(\sim 800 \mathrm{nM})$ in wild-type and CAPS DKO cells. We estimated the rate constants for secretion (Sorensen et al., 2002), and these are plotted versus the calcium concentration in Figure $4 B$. For both wild-type and CAPS DKO responses, estimated rate constants rose with the calcium concentration and were similar over the entire range tested. Thus, CAPS does not alter calcium sensing during secretion.

To determine whether there were qualitative changes in vesicle fusion, we examined the properties of single amperometric events. An example of such an experiment is shown in Figure $5 A$. There was no significant difference between wild-type and CAPS DKO cells in the amplitude, half width, rise time, single spike charge, or "foot" parameters of the amperometric events (Fig. $5 B-F)$. The only difference we observed between wild-type and CAPS DKO cells in amperometric events was in the frequency of events in calcium-perfused chromaffin cells (Fig. $5 G$ ), consistent with the observations in CAPS-1 knock-out cells, which we have reported previously (Speidel et al., 2005), and with reports in PC1 2 cells after CAPS knockdown (Fujita et al., 2007). Thus, our results indicate a specific deficit in RRP generation in CAPS DKO cells.

To rule out the possibility that our results are an artifact because of secondary consequences of the CAPS deletion, we reintroduced CAPS-1 into chromaffin cells from CAPS DKO mice, using the Semliki Forest virus expression system. In flash experiments, the characteristics of CAPS DKO cells were similar to those described above, exhibiting a small burst response of $\sim 47$ fF (Fig. $6 A)(n=15)$, with an RRP of $22.1 \pm 5.7 \mathrm{fF}$, an SRP of $25.2 \pm 8.4 \mathrm{fF}$, and little sustained release $(2.4 \pm 1.5 \mathrm{fF} / \mathrm{s})$ (Fig. $6 B$ ). Recordings from CAPS DKO cells expressing CAPS-1 showed significantly stronger secretion, with a burst that was approximately five times larger than that observed in CAPS DKO cells (226 fF; $n=17$ ) (Fig. 6A). The RRP of the DKO cells expressing CAPS- 1 was $155.6 \pm 23 \mathrm{fF}$, greater than that of the wild-type cells (Fig. 1), whereas the SRP $(69.1 \pm 8.3 \mathrm{fF})$ and sustained release $(20.9 \pm 3.3 \mathrm{fF} / \mathrm{s})$ were similar to that observed in wild-type cells (Figs. 1, 6B). The capacitance changes were associated with comparable amperometric responses as well (Fig. 6A). This result emphasizes the selective effect of CAPS on the filling of the RRP described in Figures 1 and 3. The difference in release time constants of the RRP approached significance (CAPS DKO, $40 \mathrm{~ms}$; CAPS -1 rescue, $27 \mathrm{~ms} ; p>0.05$ ), but not in the SRP (CAPS DKO, $630 \mathrm{~ms}$; CAPS-1 rescue, $461 \mathrm{~ms} ; p>0.2$ ).

\section{Discussion}

Mouse chromaffin cells from which both CAPS-1 and CAPS-2 are deleted exhibit a large deficit in exocytosis. The deficit in the RRP is pronounced, whereas that in the SRP is not statistically significant. Because there was no difference in vesicle density or distribution, or in the number of morphologically docked vesicles, we conclude that there is a deficit in priming in CAPS DKO cells. Because an RRP and an SRP (albeit reduced) are present in CAPS DKO, priming must occur. 

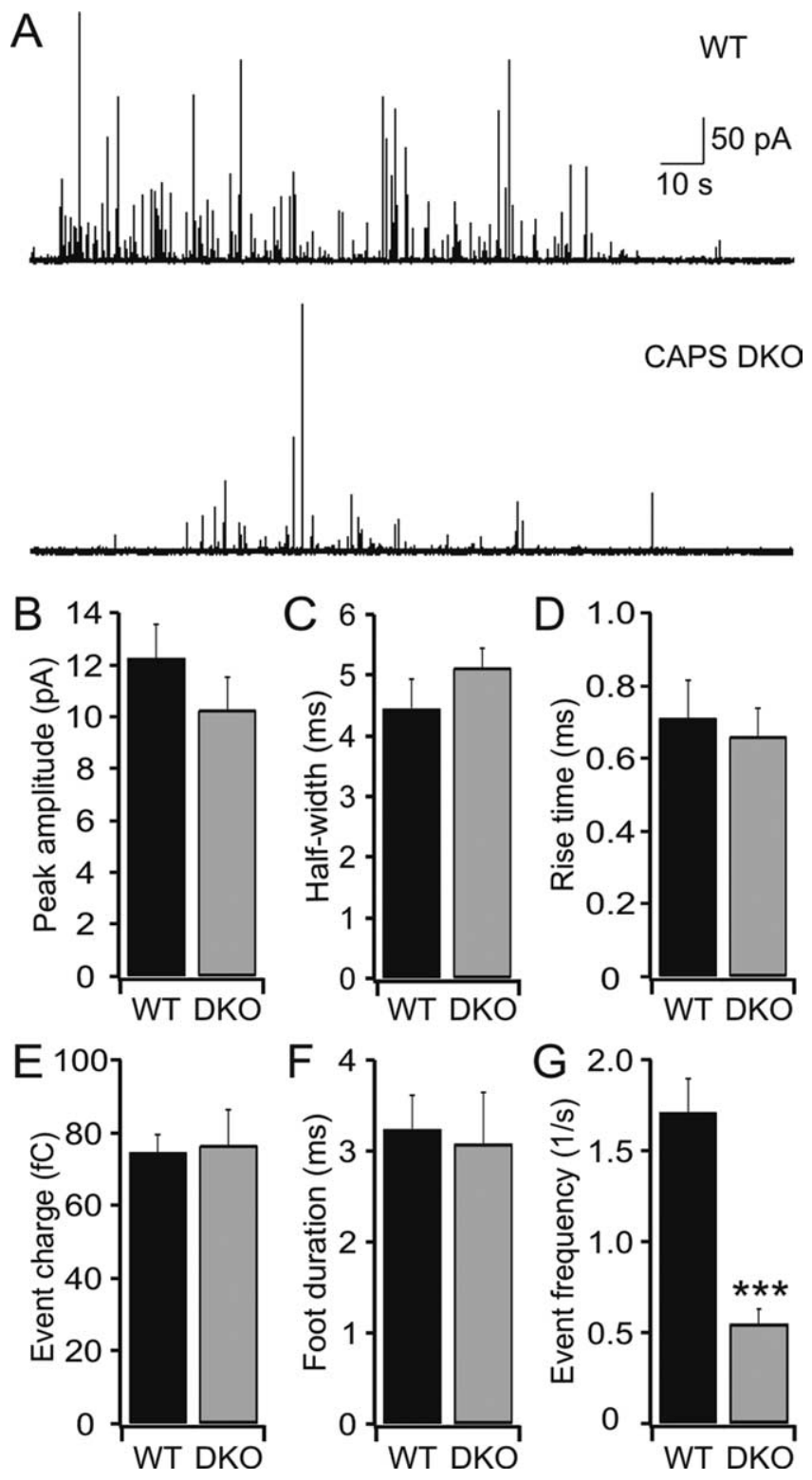

Figure 5. Amperometric spike parameters are normal in CAPS DKO chromaffin cells. $A$, Example of amperometric activity during calcium perfusion $(\sim 4 \mu \mathrm{M}$ ) in wild-type (top trace) and DKO (bottom trace) cells. $\boldsymbol{B}-\boldsymbol{F}$, There was no difference in the following: the amplitude of amperometric responses between wild-type ( $n=12,2151$ events) and DKO cells ( $n=10,479$ events) ( $\boldsymbol{B}$ ); the half-width of amperometric spikes for DKO cells compared with wild type cells (C); the rise time of amperometric responses was similar in wild type and CAPS DKO chromaffin cells $(\boldsymbol{D})$; the catecholamine content of the vesicles was also similar in wild-type and CAPS DKO cells $(\boldsymbol{E})$; the duration of so-called foot events in the CAPS DKO cells compared with those events observed in wild-type cells $(\boldsymbol{F})$. $\mathbf{G}$, There was a strongly significant difference in the frequency of amperometric events compared with those observed in wild-type chromaffin cells during calcium perfusion $\left(4 \mu \mathrm{m}^{* * *} p<0.001\right)$. The mean median values \pm SEM are shown. WT, Wild type.

Our dual flash experiments indicate that while refilling occurs, recovery of the RRP after strong secretory activity was greatly reduced in CAPS DKO cells compared with wild-type cells. Surprisingly, SRP filling approaches wild-type levels at short intervals, indicating that priming into the SRP proceeds normally in CAPS DKO cells. The lack of a change in morphologically docked vesicles and the efficient filling of the SRP are not consistent with a deficit in docking such as that observed by Zhou et al. (2007) in C. elegans neurons. Despite filling of the SRP, the RRP does not
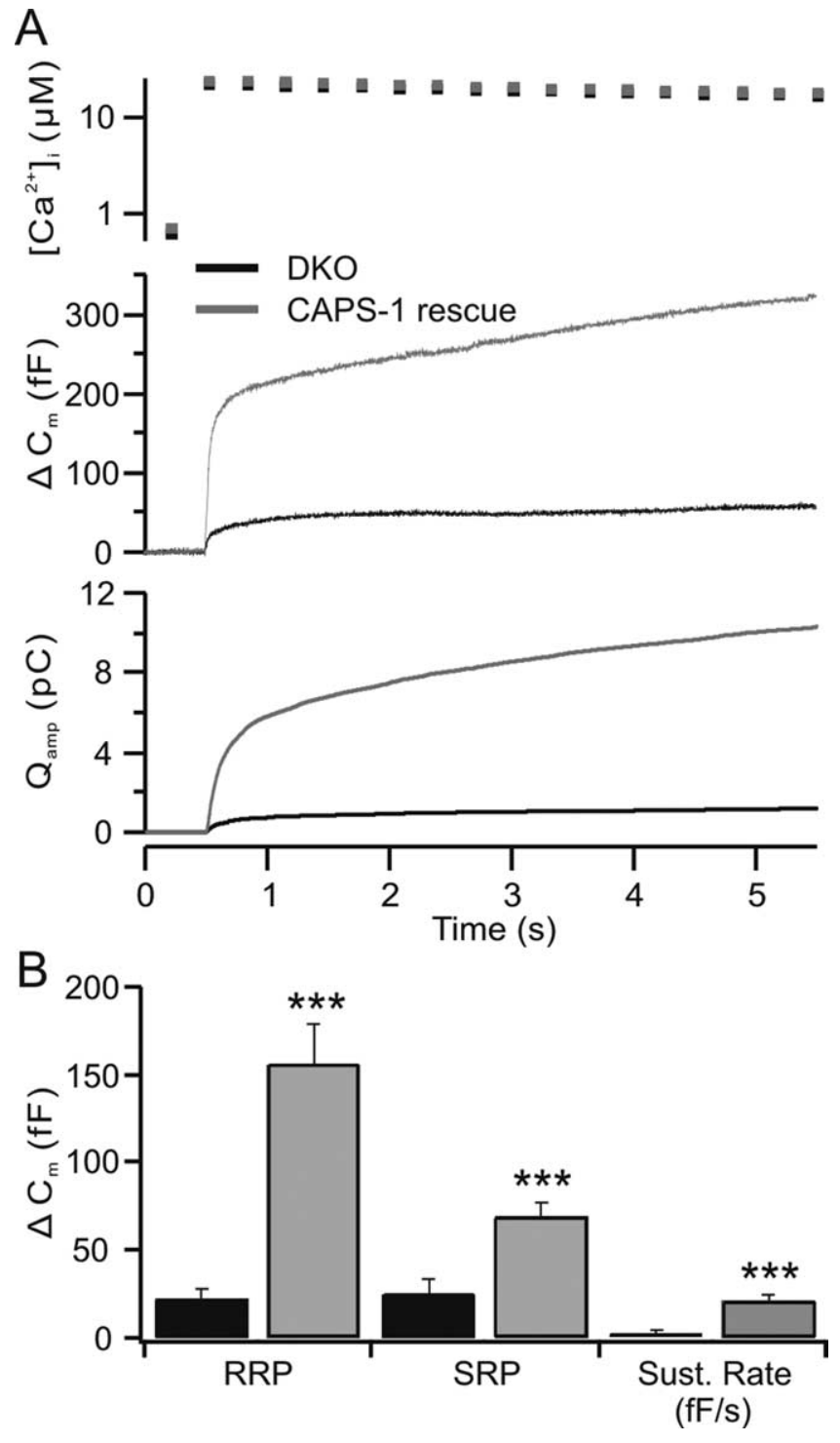

Figure 6. CAPS-1 reintroduction rescues the RRP and sustained release in CAPS DKO chromaffin cells. A, Flash photolysis of NP-EGTA was performed in DKO chromaffin cells. These cells were used as controls for cells from littermates in which CAPS-1 was expressed using the Semliki Forest virus as vector. DKO cells exhibited low levels of secretion $\left(\Delta C_{m}\right)$ with no sustained component, whereas CAPS-1-expressing cells exhibited approximately fivefold secretion and a robust sustained component. The calcium levels reached in both groups were similar (top trace). The cumulative integral of amperometric responses (catecholamine release; $Q_{a m p}$ ) observed during the capacitance change was also greatly enhanced after CAPS-1 expression. $\boldsymbol{B}$, The mean values \pm SEM of the RRP, SRP $\left({ }^{* * *} p<0.001\right)$ and sustained phases in the above described rescue experiments. Sust. Rate, sustained rate.

adequately refill. Because the burst size at ISIs of 2 min or $45 \mathrm{~s}$ is smaller than that at an ISI of $15 \mathrm{~s}$ in CAPS DKO cells, and the RRP is not refilled at $45 \mathrm{~s}$, it is probable that the excess SRP becomes unprimed in mutant cells.

A defect in priming from the SRP to the RRP, or a lack of stability of the RRP could explain this result and the lack of RRP refilling, as well as the decrease in secretory burst size in CAPS DKO cells. Thus, in wild-type cells the secretory burst (i.e., the sum of SRP and RRP) remains relatively constant, whereas in CAPS DKO cells, the burst at an ISI of $15 \mathrm{~s}$ is larger than that after a $25 \mathrm{~s}$ or $45 \mathrm{~s}$ ISI. A similar increase in SRP in wild-type cells is translated to a filled RRP, because the decrease in SRP over time is similar to the gain in the RRP, whereas only $50 \%$ of the decrease 
in SRP in CAPS DKO cells is translated into a gain in RRP, indicating that primed vesicles are lost without being secreted in the absence of CAPS. Although pool refilling occurs in CAPS DKO cells, there is little sustained release at intracellular calcium levels that normally would release primed vesicles. This is underscored by the lack of sustained secretion despite overfilling of the SRP, which can be explained if sustained release comes from the RRP rather than from the SRP. We cannot rule out that sustained release is masked, to a degree, by endocytosis.

The calcium dependence of release, as determined by calcium ramp stimulation, is the same in DKO cells and wild-type cells. As in the flash experiments, the ramp stimulation caused robust secretion in wild-type chromaffin cells. Secretion in the CAPS DKO cells during the ramp stimulation was $\sim 20 \%$ of that observed in wild-type cells, a greater deficit than that observed in the flash experiments $(\sim 46 \%)$. Whereas secretion from CAPS DKO cells could be fit by a single sigmoid, that of wild-type cells required a fit with two sigmoid components. The first component of the wild-type response had a time course similar to that of CAPS DKO cells. The midpoint of both events occurred at $\sim 5 \mathrm{~s}$ after the start of the ramp. This component probably corresponds to the burst phase during which the RRP and SRP are released. The differences in release rates are not apparent in these experiments because of the slow increase in calcium and the differing calcium dependence of the two releasable pools. The release of the two pools tends to merge under these conditions.

The reported $K_{\mathrm{d}}$ values for release of the SRP and the RRP are 8 and $12.7 \mu \mathrm{M}$, respectively (Voets, 2000). Thus, our calcium stimulus was adequate to release both pools, and in the flash experiments, this clearly occurs. In ramp experiments, the total burst in the CAPS DKO cells was $\sim 80 \mathrm{fF}$, whereas the burst in the wild-type cells was $\sim 200 \mathrm{fF}$, similar to those observed in flash experiments. The ratio of wild-type burst size to that of the DKO was $\sim 2.5$, also similar to that observed in the flash experiment $(\sim 2)$. The remaining secretion, accounted for in the second phase observed in wild-type cells, consists mainly of the sustained phase because, based on the curve fit, it occurred with a delay, after the burst phase (half-time near $8 \mathrm{~s}$ ). Because the calcium concentration reached in the ramp protocol is similar to that achieved after the flash, the greater decrease in net secretion observed in CAPS DKO cells after ramp stimulation is likely attributable to a lack of sustained release in the DKO.

The chromaffin granule priming process is calcium dependent, with an estimated $K_{\mathrm{d}}$ for calcium of $2.3 \mu \mathrm{M}$ (Moser and Neher, 1997). Thus, priming is promoted at increased intracellular calcium levels. In hippocampal neurons lacking CAPS, deficits in glutamatergic neurotransmission can be partially reversed by increasing extracellular calcium (Jokusch et al., 2007). The lack of sustained release is not attributable to a lack of calcium per se, because in CAPS DKO chromaffin cells, the SRP was released. Modeling of secretion in chromaffin cells (Sorensen, 2004) indicates that sustained release originates from the SRP, because priming to the SRP is thought to precede filling of the RRP. If this is the case, a lack of sustained release may indicate that secretion out of the SRP is depressed in CAPS DKO cells. As stated above it is also possible that the sustained phase originates from the RRP.

Expression of CAPS- 1 in the CAPS-DKO cells rescued the $\mathrm{RRP}$, the SRP, and sustained release, with a more pronounced effect on the RRP. This finding indicates that the observed deficits are attributable to the lack of CAPS, and not to indirect effects of the CAPS loss (e.g., on cell differentiation and development), and that CAPS in chromaffin cells facilitates the filling of the RRP and supports sustained release.
The mechanism of CAPS function in priming remains unclear. Although priming by Munc13 requires the presence of a "MUN" domain that includes both MHDs (Basu et al., 2005; Madison et al., 2005; Stevens et al., 2005), CAPS isoforms contain only one MHD. Basu et al. (2005) have suggested that the area of homology extends beyond the MHDs, and thus an interaction of CAPS with the fusion machinery in a similar manner to that of Munc-13 cannot be ruled out. Hammarlund et al. (2008) have reported that the open form of syntaxin can rescue the docking phenotype induced by UNC31 mutation in C. elegans. This result provides evidence that CAPS may indeed interact with SNARE (soluble $\mathrm{N}$-ethylmaleimide-sensitive factor attachment protein receptor) complexes in a manner similar to that of Munc-13. Although in a physiological context this process is defined as priming (i.e., transfer of vesicles into releasable pools), anatomical EM studies with improved resolution define this process as morphological docking. In the future, the dynamic analysis of vesicle movement at the plasma membrane by evanescent wave microscopy might help to resolve this issue.

CAPS DKO chromaffin cells are able to generate an exocytotic burst but exhibit very little sustained release. The CAPS DKO cells show a deficit in the transition of vesicles from the SRP into the RRP. Refilling of the RRP occurs very slowly, and this may allow loss of primed vesicles in the SRP by transition back to the unprimed pool resulting in decreased pool size. The successful rescue of the RRP and sustained release indicates that the observed effects are not attributable to developmental deficits and that CAPS does indeed function in priming from the SRP to the RRP. These results are consistent with a model in which priming to one releasable pool, the SRP, proceeds without CAPS participation. A second step in the priming process, priming to the RRP, is facilitated by CAPS, although this transition can occur in the absence of CAPS.

\section{References}

Ann K, Kowalchyk JA, Loyet KM, Martin TF (1997) Novel Ca ${ }^{2+}$-binding protein (CAPS) related to UNC-31 required for $\mathrm{Ca}^{2+}$-activated exocytosis. J Biol Chem 272:19637-19640.

Aravamudan B, Fergestad T, Davis WS, Rodesch CK, Broadie K (1999) Drosophila Unc-13 is essential for synaptic transmission. Nat Neurosci 2:965-971.

Ashery U, Betz A, Xu T, Brose N, Rettig J (1999) An efficient method for infection of adrenal chromaffin cells using the Semliki Forest virus gene expression system. Eur J Cell Biol 78:525-532.

Ashery U, Varoqueaux F, Voets T, Betz A, Thakur P, Koch H, Neher E, Brose N, Rettig J (2000) Munc13-1 acts as a priming factor for large dense-core vesicles in bovine chromaffin cells. EMBO J 19:3586-3596.

Augustin I, Betz A, Herrmann C, Jo T, Brose N (1999) Differential expression of two novel Munc13 proteins in rat brain. Biochem J 337:363-371.

Avery L, Bargmann CI, Horvitz HR (1993) The Caenorhabditis elegans unc-31 gene affects multiple nervous system-controlled functions. Genetics 134:455-464.

Basu J, Shen N, Dulubova I, Lu J, Guan R, Guryev O, Grishin NV, Rosenmund C, Rizo J (2005) A minimal domain responsible for Munc13 activity. Nat Struct Mol Biol 12:1017-1018.

Berwin B, Floor E, Martin TF (1998) CAPS (mammalian UNC-31) protein localizes to membranes involved in dense-core vesicle exocytosis. Neuron 21:137-145.

Burgoyne RD, Morgan A (2003) Secretory granule exocytosis. Physiol Rev 83:581-632.

Cisternas FA, Vincent JB, Scherer SW, Ray PN (2003) Cloning and characterization of human CADPS and CADPS2, new members of the $\mathrm{Ca}^{2+}$. dependent activator for secretion protein family. Genomics 81:279-291.

Elhamdani A, Martin TF, Kowalchyk JA, Artalejo CR (1999) $\mathrm{Ca}^{2+}$ dependent activator protein for secretion is critical for the fusion of dense-core vesicles with the membrane in calf adrenal chromaffin cells. J Neurosci 19:7375-7383. 
Fujita Y, Xu A, Xie L, Arunachalam L, Chou TC, Jiang T, Chiew SK, Kourtesis J, Wang L, Gaisano HY, Sugita S (2007) $\mathrm{Ca}^{2+}$-dependent activator protein for secretion 1 is critical for constitutive and regulated exocytosis but not for loading of transmitters into dense core vesicles. J Biol Chem 282:21392-21403.

Gracheva EO, Burdina AO, Touroutine D, Berthelot-Grosjean M, Parekh H, Richmond JE (2007) Tomosyn negatively regulates CAPS-dependent peptide release at Caenorhabditis elegans synapses. J Neurosci 27:10176-10184.

Grishanin RN, Klenchin VA, Loyet KM, Kowalchyk JA, Ann K, Martin TF (2002) Membrane association domains in $\mathrm{Ca}^{2+}$-dependent activator protein for secretion mediate plasma membrane and dense-core vesicle binding required for $\mathrm{Ca}^{2+}$-dependent exocytosis. J Biol Chem 277:22025-22034

Grishanin RN, Kowalchyk JA, Klenchin VA, Ann K, Earles CA, Chapman ER, Gerona RR, Martin TF (2004) CAPS acts at a prefusion step in densecore vesicle exocytosis as a PIP2 binding protein. Neuron 43:551-562.

Hammarlund M, Watanabe S, Schuske K, Jorgensen EM (2008) CAPS and syntaxin dock dense core vesicles to the plasma membrane in neurons. J Cell Biol 180:483-491.

Hay JC, Martin TF (1992) Resolution of regulated secretion into sequential MgATP-dependent and calcium-dependent stages mediated by distinct cytosolic proteins. J Cell Biol 119:139-151.

Jockusch WJ, Speidel D, Sigler A, Sorensen JB, Varoqueaux F, Rhee JS, Brose N (2007) CAPS-1 and CAPS-2 are essential synaptic vesicle priming proteins. Cell 131:796-808.

Kang L, He Z, Xu P, Fan J, Betz A, Brose N, Xu T (2006) Munc13-1 is required for the sustained release of insulin from pancreatic beta cells. Cell Metab 3:463-468.

Koch H, Hofmann K, Brose N (2000) Definition of Munc13-homologydomains and characterization of a novel ubiquitously expressed Munc13 isoform. Biochem J 349:247-253.

Madison JM, Nurrish S, Kaplan JM (2005) UNC-13 interaction with syntaxin is required for synaptic transmission. Curr Biol 15:2236-2242.

Moser T, Neher E (1997) Rapid exocytosis in single chromaffin cells recorded from mouse adrenal slices. J Neurosci 17:2314-2323.

Renden R, Berwin B, Davis W, Ann K, Chin C, Kreber R, Ganetzky B, Martin TF, Broadie K (2001) Drosophila CAPS is an essential gene that regulates dense-core vesicle release and synaptic vesicle fusion. Neuron 31:421-437.
Rettig J, Neher E (2002) Emerging roles of presynaptic proteins in $\mathrm{Ca}^{++}$ triggered exocytosis. Science 298:781-785.

Richmond JE, Davis WS, Jorgensen EM (1999) UNC-13 is required for synaptic vesicle fusion in C. elegans. Nat Neurosci 2:959-964

Rupnik M, Kreft M, Sikdar SK, Grilc S, Romih R, Zupancic G, Martin TF, Zorec R (2000) Rapid regulated dense-core vesicle exocytosis requires the CAPS protein. Proc Natl Acad Sci USA 97:5627-5632.

Sorensen JB (2004) Formation, stabilisation and fusion of the readily releasable pool of secretory vesicles. Pflügers Arch 448:347-362.

Sorensen JB, Matti U, Wei SH, Nehring RB, Voets T, Ashery U, Binz T, Neher E, Rettig J (2002) The SNARE protein SNAP-25 is linked to fast calcium triggering of exocytosis. Proc Natl Acad Sci USA 99:1627-1632.

Speese S, Petrie M, Schuske K, Ailion M, Ann K, Iwasaki K, Jorgensen EM, Martin TF (2007) UNC-31 (CAPS) is required for dense-core vesicle but not synaptic vesicle exocytosis in Caenorhabditis elegans. J Neurosci 27:6150-6162.

Speidel D, Varoqueaux F, Enk C, Nojiri M, Grishanin RN, Martin TF, Hofmann K, Brose N, Reim K (2003) A family of $\mathrm{Ca}^{2+}$-dependent activator proteins for secretion: comparative analysis of structure, expression, localization, and function. J Biol Chem 278:52802-52809.

Speidel D, Bruederle CE, Enk C, Voets T, Varoqueaux F, Reim K, Becherer U, Fornai F, Ruggieri S, Holighaus Y, Weihe E, Bruns D, Brose N, Rettig J (2005) CAPS1 regulates catecholamine loading of large dense-core vesicles. Neuron 46:75-88.

Stevens DR, Wu ZX, Matti U, Junge HJ, Schirra C, Becherer U, Wojcik SM, Brose N, Rettig J (2005) Identification of the minimal protein domain required for priming activity of Munc13-1. Curr Biol 15:2243-2248.

Tandon A, Bannykh S, Kowalchyk JA, Banerjee A, Martin TF, Balch WE (1998) Differential regulation of exocytosis by calcium and CAPS in semi-intact synaptosomes. Neuron 21:147-154.

Voets T (2000) Dissection of three $\mathrm{Ca}^{2+}$-dependent steps leading to secretion in chromaffin cells from mouse adrenal slices. Neuron 28:537-545.

Walent JH, Porter BW, Martin TF (1992) A novel $145 \mathrm{kd}$ brain cytosolic protein reconstitutes $\mathrm{Ca}^{2+}$-regulated secretion in permeable neuroendocrine cells. Cell 70:765-775.

Zhou KM, Dong YM, Ge Q, Zhu D, Zhou W, Lin XG, Liang T, Wu ZX, Xu T (2007) PKA activation bypasses the requirement for UNC-31 in the docking of dense core vesicles from C. elegans neurons. Neuron 56:657669. 